\title{
FAP-overexpressing fibroblasts produce an extracellular matrix that enhances invasive velocity and directionality of pancreatic cancer cells
}

\author{
Hyung-Ok Lee ${ }^{1}$, Stefanie R Mullins', Janusz Franco-Barraza², Matthildi Valianou², Edna Cukierman ${ }^{2 *}$ and \\ Jonathan D Cheng ${ }^{1 *}$
}

\begin{abstract}
Background: Alterations towards a permissive stromal microenvironment provide important cues for tumor growth, invasion, and metastasis. In this study, Fibroblast activation protein (FAP), a serine protease selectively produced by tumor-associated fibroblasts in over $90 \%$ of epithelial tumors, was used as a platform for studying tumor-stromal interactions.

We tested the hypothesis that FAP enzymatic activity locally modifies stromal ECM (extracellular matrix) components thus facilitating the formation of a permissive microenvironment promoting tumor invasion in human pancreatic cancer.
\end{abstract}

Methods: We generated a tetracycline-inducible FAP overexpressing fibroblastic cell line to synthesize an in vivolike 3-dimensional (3D) matrix system which was utilized as a stromal landscape for studying matrix-induced cancer cell behaviors. A FAP-dependent topographical and compositional alteration of the ECM was characterized by measuring the relative orientation angles of fibronectin fibers and by Western blot analyses. The role of FAP in the matrix-induced permissive tumor behavior was assessed in Panc-1 cells in assorted matrices by time-lapse acquisition assays. Also, $\mathrm{FAP}^{+}$matrix-induced regulatory molecules in cancer cells were determined by Western blot analyses.

Results: We observed that FAP remodels the ECM through modulating protein levels, as well as through increasing levels of fibronectin and collagen fiber organization. FAP-dependent architectural/compositional alterations of the ECM promote tumor invasion along characteristic parallel fiber orientations, as demonstrated by enhanced directionality and velocity of pancreatic cancer cells on $\mathrm{FAP}^{+}$matrices. This phenotype can be reversed by inhibition of FAP enzymatic activity during matrix production resulting in the disorganization of the ECM and impeded tumor invasion. We also report that the $\mathrm{FAP}^{+}$matrix-induced tumor invasion phenotype is $\beta_{1}$-integrin/ FAK mediated.

Conclusion: Cancer cell invasiveness can be affected by alterations in the tumor microenvironment. Disruption of FAP activity and $\beta_{1}$-integrins may abrogate the invasive capabilities of pancreatic and other tumors by disrupting the FAP-directed organization of stromal ECM and blocking $\beta_{1}$-integrin dependent cell-matrix interactions. This provides a novel preclinical rationale for therapeutics aimed at interfering with the architectural organization of tumor-associated ECM. Better understanding of the stromal influences that fuel progressive tumorigenic behaviors may allow the effective future use of targeted therapeutics aimed at disrupting specific tumor-stromal interactions.

\footnotetext{
* Correspondence: edna.cukierman@fccc.edu; Jonathan.Cheng@fccc.edu 'Department of Medical Oncology, Fox Chase Cancer Center, 333 Cottman Avenue, Philadelphia, Pennsylvania 19111, USA

${ }^{2}$ Cancer Biology Program, Fox Chase Cancer Center, 333 Cottman Avenue, Philadelphia, Pennsylvania 19111, USA

Full list of author information is available at the end of the article
} 


\section{Background}

Increasing evidence demonstrates the significance of the tumor microenvironment for tumor initiation and progression [1-6]. The tumor microenvironment is characterized by a heterogeneous complex of cellular and acellular components including tumor-associated fibroblasts, immune and endothelial cells, soluble cytokines, chemokines and proteases, as well as a characteristically remodeled ECM [7]. These components act in a coordinated manner to regulate the growth and differentiation of adjacent cells, thus alterations in the stromal microenvironment towards a permissive environment provide important cues for tumor growth, invasion, and metastasis $[7,8]$. In fact, the majority of proteases and stromal factors associated with malignant tumors are secreted by the host stroma rather than by the tumor cells themselves [9-11]. One of the most selective proteins for tumor stromal fibroblasts is the Fibroblast Activation Protein (FAP).

FAP is a serine protease that contains both dipeptidyl peptidase and gelatinase/collagenage activities in vitro [12]. Because of its specific induction in tumor-associated fibroblasts in over $90 \%$ of epithelial tumors, including pancreas and breast among others, FAP was used as a platform for studying stromal specific effects on tumor behaviors [13-18]. Previously, we reported that FAP overexpression by tumor cells results in increased tumorigenicity and tumor growth [16] and its enzymatic activity played an important role in the promotion of tumor growth in mouse model [17]. Although several studies have shown that FAP expression in human melanoma cell lines or hepatic stellate cells promotes an invasive phenotype through cell adhesion pathways [13-15], it is not clear how FAP expressing fibroblast-specific signals prepare a permissive stromal microenvironment and how modified ECMs influence cancer cell behavior in vitro.

Studies in several human cancer types describing alterations in stromal cells and their ECM compositions suggest that changes in the microenvironment and tissue architecture contribute to tumorigenesis [19]. In vivo, the mesenchymal ECM is comprised of several proteins including collagens I, III and fibronectin, which assemble in an intricate fibrillar network and are engaged by transmembrane receptors. For example, integrins transmit biochemical and mechanical stimuli from the matrix to the cytoskeleton of the cell and back to the ECM, triggering distinct intracellular signaling pathways that control proliferation, survival, and migration [20]. In fact, it has been shown that both desmoplastic fibronectin and collagen I fibers often align in parallel patterns in response to tumorigenesis [21,22], and these fibers are engaged by integrin heterodimers in pancreatic and other cancers $[6,20]$, suggesting that cell behavior can be affected by the underlying stromal substrates via integrin engagement. Thus, alteration of the stromal ECM composition in cancers may be linked to cancer progression through tissue remodeling processes [23]. Here, we show that FAP enzymatic activity locally modifies stromal ECM components thus facilitating the formation of a permissive microenvironment promoting tumor invasion on human pancreatic cancer.

\section{Methods}

\section{Cell lines and murine xenograft model}

All cell lines used in this study were originally purchased from ATCC or obtained from the Cell Culture Facility at Fox Chase Cancer Center. Three C.B17/Icrscid mice were subcutaneously injected with $2 \times 10^{6}$ cells of each pancreatic cell line (Panc-1, Capan-1, AsPC-1, and HPAF-II). After 5 weeks inoculation, tumors were harvested for immunohistochemistry analysis.

\section{Stable transfection of fap in NIH-3T3 fibroblasts}

Mouse fap gene was cloned downstream of the Tetresponse promoter in a tetracycline-inducible expression vector pTRE (a kind gift from Dr. Teresa Ramirez-Montagut, Memorial Sloan-Kettering Cancer Center, NY). This construct was co-transfected into NIH-3T3 cells with rtTA plasmid (pUHD172-1 neo) that encodes the pTRE promoter-binding transactivator, thus murine FAP expression was induced by adding Doxycycline (Dox, $2 \mu \mathrm{g} / \mathrm{ml}$ ) into complete DMEM medium containing $10 \%$ Tet system approved Fetal Bovine Serum (Clontech, CA).

\section{Isolation of human pancreatic stellate cells and matched pancreatic adenocarcinoma-associated fibroblasts}

Fresh surgical tissue (decoded) samples from a pancreatic Whipple conducted at the Fox Chase Cancer Center was delivered with the assistance of the Protocol Laboratory and the Biosample Repository Facility following protocols approved by the Institutional Review Board. Tissue samples corresponding to pancreatic adenocarcinoma and distant (normal) pancreas were rinsed in cold PBS containing $100 \mu \mathrm{g} / \mathrm{ml}$ streptomycin and 100 $\mathrm{U} / \mathrm{ml}$ penicillin. The two types of samples were carefully minced and incubated overnight with $0.2 \%$ collagenase at $37^{\circ} \mathrm{C}$ for digestive dissociation. The digested material was subjected to centrifugation at $1200 \mathrm{rpm}$ for $5 \mathrm{~min}$, thus precipitating a fibroblast-enriched fraction. This fraction was filtered through a series of $100 \mu \mathrm{m}$ followed by $40 \mu \mathrm{m}$ cell-strainer (BD Bioscience) before culturing in DMEM containing $10 \% \mathrm{FBS}, 100 \mathrm{U} / \mathrm{ml}$ penicillin, 100 $\mu \mathrm{g} / \mathrm{ml}$ streptomycin and $2 \mathrm{mM} \mathrm{L}$-glutamine at $37^{\circ} \mathrm{C}$ using a humidified atmosphere and $5 \% \mathrm{CO}_{2}$ for a period of 4 hours before removing the non adherent cells. Cell 
homogeneity was confirmed by direct microscopic observations, while cells were designated as fibroblastic following confirmation of mesenchymal marker vimentin expression, as well as absence of epithelial marker cytokeratin 19 expression. In addition, normal fibroblasts were characterized as pancreatic stellate cells following confirmation of uptake and storage of vitamin A, by auto-fluorescence stemming from retinyl acetate (Sigma) containing droplets [24]. The resultant (PaSCs) and pancreatic tumor-associated fibroblasts (which were confirmed to have lost the vitamin A droplets) were used for self-derived matrix characterization.

\section{Western analysis of FAP induction in fibroblasts}

FAP-transfected fibroblasts were harvested at different time points $(0,1,2,4,6,8$, and 10 days) in the presence or absence of Dox. Total protein was extracted using M-Per reagent (Pierce, IL), resolved by $4-12 \%$ SDSPAGE under reducing conditions (Invitrogen, CA), and blotted with rabbit monoclonal anti-mouse FAP antibody $(0.08 \mu \mathrm{g} / \mathrm{ml})$. Immuno positive bands were labeled using goat anti-rabbit-HRP (3000×, Amersham Bioscience, UK) and visualized by ECL reagent (Pierce, IL). Purified murine recombinant FAP protein $(92 \mathrm{kD})$ and parental NIH-3T3 cell lysate were used as positive and negative controls, respectively.

\section{Fibroblast-derived 3D matrix production}

All fibroblasts were seeded at a concentration of $7 \times 10^{5}$ cells per sample onto $35 \mathrm{~mm}$ plates pre-coated with $0.2 \%$ gelatin. Confluent fibroblastic cultures were treated with media supplemented with $50 \mu \mathrm{g} / \mathrm{ml}$ ascorbic acid (and Dox when necessary) every other day for 8 days to obtain un-extracted 3D cultures. Alkaline detergent treatment $\left(0.5 \%\right.$ Triton X-100, $20 \mathrm{mM} \mathrm{NH}_{4} \mathrm{OH}$ in PBS) for 5 minutes at $37^{\circ} \mathrm{C}$ gave rise to cell-free in vivo-like $3 \mathrm{D}$ matrices $[25,26]$. For control, FAP-transfected fibroblasts were used to make $\mathrm{FAP}^{-}$matrix in the absence of Dox. To make FAP+inhibitor matrix, FAP-specific small molecule inhibitor naphthalenecarboxy-Gly-boroPro (400 $\mu \mathrm{M}$, provided by Dr. William Bachovchin, Tufts University, MA) was added to the media during matrix production.

\section{Analysis of fibronectin fiber orientation}

For indirect immunofluorescent labeling of matrix fibers, un-extracted 3D cultures were prepared on glass cover slips as described [21]. Cells were stained with rabbit anti-mouse fibronectin antibody $(25 \mu \mathrm{g} / \mathrm{ml}$, Abcam, UK), a donkey anti-rabbit Cy5 conjugated antibody $(15 \mu \mathrm{g} / \mathrm{ml}$, Jackson ImmunoResearch, PA) and DAPI.

From two independent experiments with duplicate samples, minimum of 5 images per experimental sample were obtained using a z-stack function of the spinning disc microscope (PerkinElmer Life Sciences, PA). Each slice measured $0.5 \mu \mathrm{m}$ and stacks were reconstituted as a maximum projection using the MetaMorph software as described in detail [21]. Fiber distributions corresponding to each experimental setting were determined by the percentage of fibers that were oriented at $10^{\circ}$ variation angles from the identified modes.

\section{In-Cell Western analysis of un-extracted 3D cultures}

FAP-transfected fibroblasts $\left(1.5 \times 10^{4}\right.$ cells/48-well plate) were cultured in the presence or absence of Dox during matrix production. Fibroblasts were fixed with $4 \%$ paraformaldehyde, permeabilized with $0.1 \%$ Triton X-100 in PBS, and stained with antibodies followed by manufacturer's directions (Li-Cor Bioscience, NE). The antibodies for this assay were tenascin C $(50 \mu \mathrm{g} / \mathrm{ml}$, Abcam, UK), $\alpha$ - SMA ( $5 \mu \mathrm{g} / \mathrm{ml}$, Sigma, MO), collagen I $(25 \mu \mathrm{g} / \mathrm{ml}$, Chemicon International, CA), fibronectin (20 $\mu \mathrm{g} / \mathrm{ml}$, Abcam, UK), $\beta$-actin (1000x, Cell Signaling Technology, MA), and GAPDH $(2 \mu \mathrm{g} / \mathrm{ml}$, Chemicon International, CA). Fluorescence-labeled secondary antibodies IRDye 680 and IRDye800CW (Li-Cor Bioscience, $\mathrm{NE}$ ) were used to scan by the Odyssey Infrared Imaging System. The protein levels were normalized by $\beta$-actin or GAPDH.

\section{Western analysis of pancreatic cancer cells cultured within assorted matrices}

Following 2 days culture on matrices, Panc- 1 cells were lysed in extraction buffer $(50 \mathrm{mM}$ Tris- $\mathrm{HCl}, \mathrm{pH} 8.8,1 \%$ SDS, $5 \mathrm{mM}$ DTT, $13 \mathrm{mM}$ iodoacetamide, $5 \mathrm{mM}$ EDTA, $150 \mathrm{mM} \mathrm{NaCl}$ ). Proteins were quantified by western blot analysis using ECL reagent (Pierce, IL) or Odyssey infrared imaging system following the manufacturer's directions (Li-Cor Bioscience, NE). The antibodies for this assay were $\beta 1$-integrin $(2500 \times$, BD Transduction Laboratories, NJ), AKT $(500 \times$, BD Transduction Laboratories, NJ), $\mathrm{pS}^{473}$-AKT $(1000 \times$, Cell Signaling Technology, MA), FAK $\left(1 \mu \mathrm{g} / \mathrm{ml}\right.$, Upstate, NY), $\mathrm{pY}^{397}$-FAK (1000x, Biosource, CA), and GAPDH $(2 \mu \mathrm{g} / \mathrm{ml}$, Chemicon International, CA). Specific activity of AKT and FAK were calculated as the ratio of the scanned optical density of phosphorylated protein/total protein. Then the ratios were normalized by GAPDH.

\section{Motility assay within the assorted 3D matrices}

As described in detail [26], tumor cells were re-plated onto the matrices and incubated overnight. Cell movements (10 15 cells), recording cells migrating both on and through the matrix, were recorded every 10 minutes during 12 hours using Nikon TE-2000U inverted microscope equipped with cool snap HQ camera. Individual cell dynamics were analyzed using the MetaMorph 
program following 4 distinctive factors: 1 ) the net path distance $(D, \mu \mathrm{m})$ by calculating the number of $\mu \mathrm{m} /$ pixel. 2) The path trajectory of an individual cell during the recording period $(\mathrm{T}, \mu \mathrm{m}) .3)$ Average velocity as the motility rate $(\mathrm{AV}, \mu \mathrm{m} / \mathrm{hr})$. 4) Directionality calculated by the $\mathrm{D} / \mathrm{T}$ ratio, which determines random $(\mathrm{D} / \mathrm{T}=$ significantly smaller than 0.5$)$ versus directional $(\mathrm{D} / \mathrm{T}=$ close to 1) migration of individual cells [27-29]. Motility experiments using the assorted matrices were performed a minimum of 3 times using different batches of matrices and following a minimum of 10 individual cells.

In order to assess the effect on motility by integrin inhibitors, motility assays were performed in the presence of functional blocking $\beta_{1}$ integrin antibody mAb13 $(50 \mu \mathrm{g} / \mathrm{ml}$, a kind gift from Dr. K. Yamada at NIH/NIDCR, Bethesda, MD) or the $\alpha_{5} \beta_{1}$-integrin blocking peptide ATN-161 (Ac-PHSCN-NH2, $50 \mu \mathrm{g} / \mathrm{ml}$, Attenuon, San Diego, CA). These experiments were performed at least 2 times using two alternative batches of matrices.

\section{Statistic analyses}

Data from 3D matrix fiber distribution were analyzed using "chi-squared test". The normalized western data were analyzed using linear regression. For the motility analysis, the average velocity, net path distance and the path trajectory were analyzed using Gamma regression, and the directionality was analyzed using linear regression.

\section{Immunohistochemistry}

Quick snap frozen tumor tissues sections (10 $\mu$ m thick) from pancreatic cancer patients and xenografted mouse tumor tissues were incubated with rat monoclonal antihuman FAP antibody D8 (20×, a kind gift from Dr. Wen-Tien Chen, State University of New York, NY) and rabbit polyclonal anti-mouse FAP antibody $(2 \mu \mathrm{g} / \mathrm{ml})$ [16], respectively. Biotin-streptavidin detection with horseradish peroxidase (BioGenex, CA) was applied for the amplification and visualization of signals following the manufacturer's directions. Note that results stemming from this method are depicted in supplemental Figure 1.

\section{Results \\ In vivo tumor-dependent stromal FAP upregulation provides the rationale to study in vitro FAP fibroblastic over-expression effects}

Some reports suggest that FAP expression can occur in both the stroma and epithelial compartments of cancers [30-33]. However, the selectivity of FAP for stromal fibroblasts, but not epithelial tumor cells, has been confirmed either by immunohistochemical studies in pancreas, colorectal and breast cancer patients $[12,34,35]$, or by RT-PCR of pancreas, lung, and renal cell xenografts [36]. To confirm the putative significance of studying FAP-expression effects in stromal matrices, we first examined FAP expression in the human pancreatic cancer patient tissues and mouse xenografts by immunohistochemistry. We observed that FAP is highly expressed on the stromal fibroblasts of human pancreatic cancer, while it is undetectable both in the epithelial cancer cells (Additional file 1, Fig. S1A) and normal tissue (not shown). In xenograft mouse models inoculating the human pancreatic cancer cell lines (HPAF-II, Capan-1, AsPC-1, and Panc-1), murine FAP expression was also found up-regulated specifically at the tumor stroma (Additional file 1, Fig. S1B). This observation confirmed the existence of a selectivity of FAP expression in tumor-associated fibroblasts and prompted us to believe that perhaps FAP is an attractive protein to study stromal effects imparted upon tumor behaviors.

\section{Stable FAP expression on naive fibroblasts}

In vivo, FAP is highly expressed on pancreatic tumor stromal fibroblasts, but its expression ex vivo on cultured primary cells is not maintained. To establish stable FAP-expressing fibroblasts, mouse fap gene was cloned under the Tet-inducible system. Induction of FAP expression was achieved as early as 24 hours following Dox treatment, and its expression was clearly maintained for at least 10 days (Figure 1A). Parental NIH$3 \mathrm{~T} 3$ cells and $\mathrm{FAP}^{+}$fibroblasts cultured in the absence of Dox showed no detectable FAP induction, allowing the use of these fibroblasts as negative controls.

\section{FAP expression on fibroblasts during 3D matrix production induces tumor stromal-like parallel orientation of fibronectin and collagen I fibers}

During the 8 days required to produce a fibroblastderived 3D matrix, clear morphological differences on fibroblasts were observed between the parental NIH$3 \mathrm{~T} 3$ and $\mathrm{FAP}^{-}$vs. $\mathrm{FAP}^{+}$fibroblasts. $\mathrm{FAP}^{+}$cells were elongated into an enhanced spindled shape, and they organized in a parallel pattern (data not shown). Since tumor-associated ECMs are organized in parallel patterns $[21,22,37]$, we tested whether FAP expression affects the topography of fibroblasts-derived ECMs by indirect immunofluorescence using anti-fibronectin (Figure 1) or anti-collagen I (Additional file 2, Fig. S2) antibodies on un-extracted matrices containing their original matrix-synthesizing fibroblasts [21]. Indeed, $\mathrm{FAP}^{+}$fibroblasts produced ECM fibers oriented in parallel patterns when compared to FAP $^{-}$matrices (Figure 1B). These patterns are reminiscent of previously observed tumor-associated patterns in vitro [21]. In addition, the level of organization of the assorted 


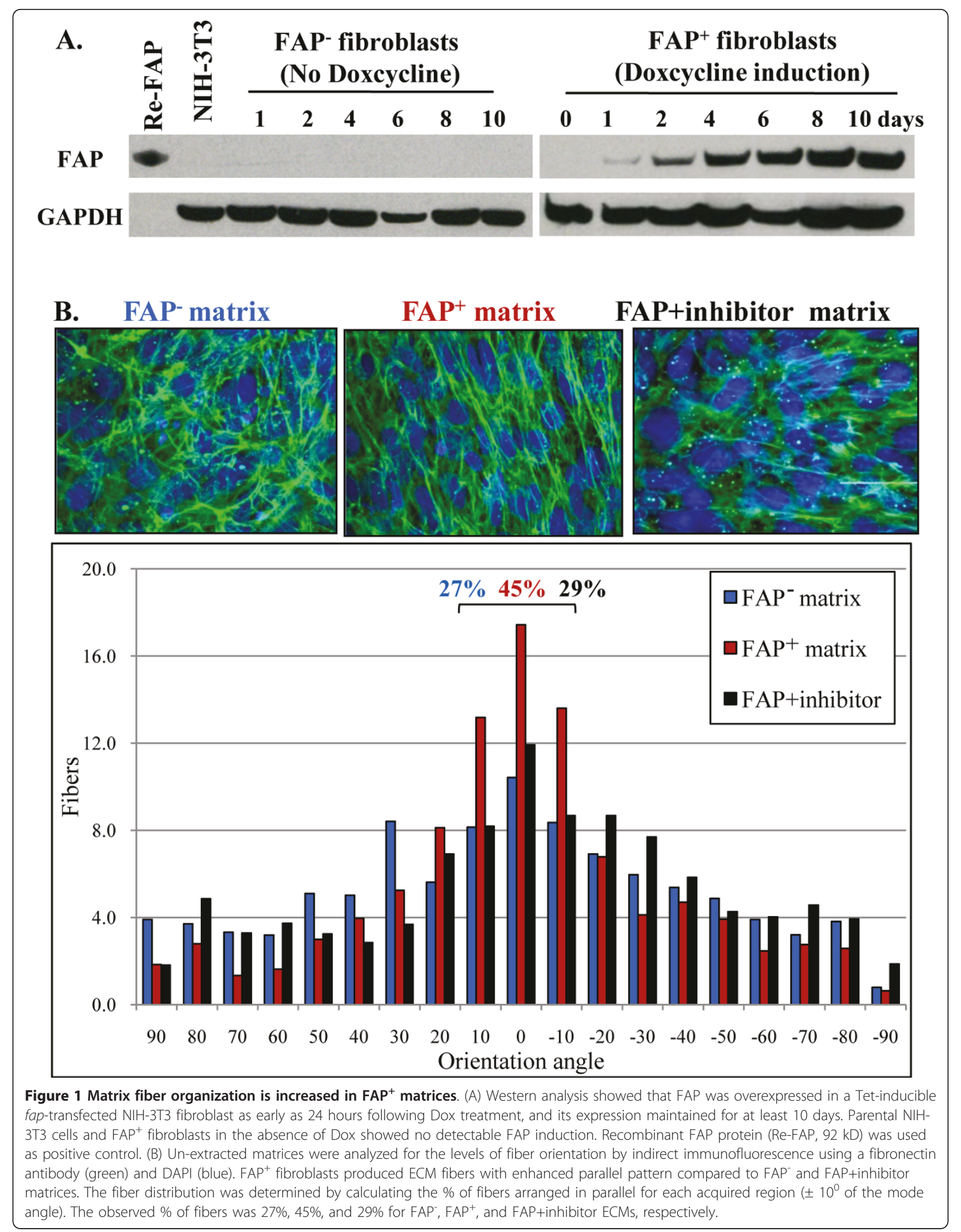


fibroblast-produced fibronectin fibers was quantified by measuring the relative orientation angles of fibers [21]. The average percent of parallel fibers that were oriented within $\pm 10^{\circ}$ of the mode angle was determined using the MetaMorph software. The measured percentages were $27 \%$ and $45 \%$ for FAP $^{-}$and FAP $^{+} 3 \mathrm{D}$ ECMs, respectively $(\mathrm{p}<0.001)$ (Figure $1 \mathrm{~B})$. Furthermore, inhibition of FAP enzymatic activity by the FAP inhibitor during the matrix production effectively reversed the FAP-induced parallel matrix orientation (29\%). Moreover, the observed architectural patterns were similar to the ones seen in desmoplastic reactions in human pancreatic cancers and in xenografted tumors formed in mice using human pancreatic cancer cells in vivo (see asterisks in Additional file 1, Fig. S1). Importantly, when assessing the architectural patterns of collagen I fibers using the FAP series of unextracted matrices in vitro, our results showed that, although the collagen I fibrillogenesis levels during matrix production ( 8 days) were not as substantial as to allow the analysis of the fiber orientation, simple microscopy observations clearly demonstrated that $\mathrm{FAP}^{+}$fibroblasts indeed affect collagen I fiber organization (Additional file 2, Fig. S2). These results suggest that the FAP enzymatic activity during matrix production is important for the topographical organization of the ECM fibers. Because of this topographical similarity to that of tumor permissive 3D ECMs [25,37], the
$\mathrm{FAP}^{+} 3 \mathrm{D}$ matrix system was used to study the mechanism of matrix-supported pancreatic cancer cell invasion.

\section{Human pancreatic stellate cells- and adenocarcinoma- derived ECMs resemble FAP null and $\mathrm{FAP}^{+}$ECMs, respectively}

It is known that FAP exhibits very restricted expression in normal adult tissue [38] and that pancreatic stellate cells are the 'normal' fibroblastic cells found in the exocrine pancreas. Activated pancreatic stellate cells (i.e., myofibroblastic cells) express $\alpha$-SMA and FAP (among other markers) and correspond to the cells believed to be responsible for the fibrosis in chronic pancreatitis and the desmoplastic reactions in pancreatic adenocarcinomas [39]. To compare our observations of the specific matrix architectures stemming from the FAP matrix series to matrices derived from normal pancreas human stellate cells and activated adenocarcinoma-associated fibroblasts, we proceeded to isolate these two types of human pancreatic fibroblastic cells from matched fresh surgical normal and pancreatic tumor (i.e., adenocarcinoma) samples (see Materials and Methods). Our results shown in Figure 2 present the standard bundle pattern of ECM fiber structures observed in FAP $^{-}$matrix. Moreover, human pancreatic adenocarcinoma-associated fibroblasts produced ECMs oriented in parallel patterns, which are similar to the patterns formed by $\mathrm{FAP}^{+}$

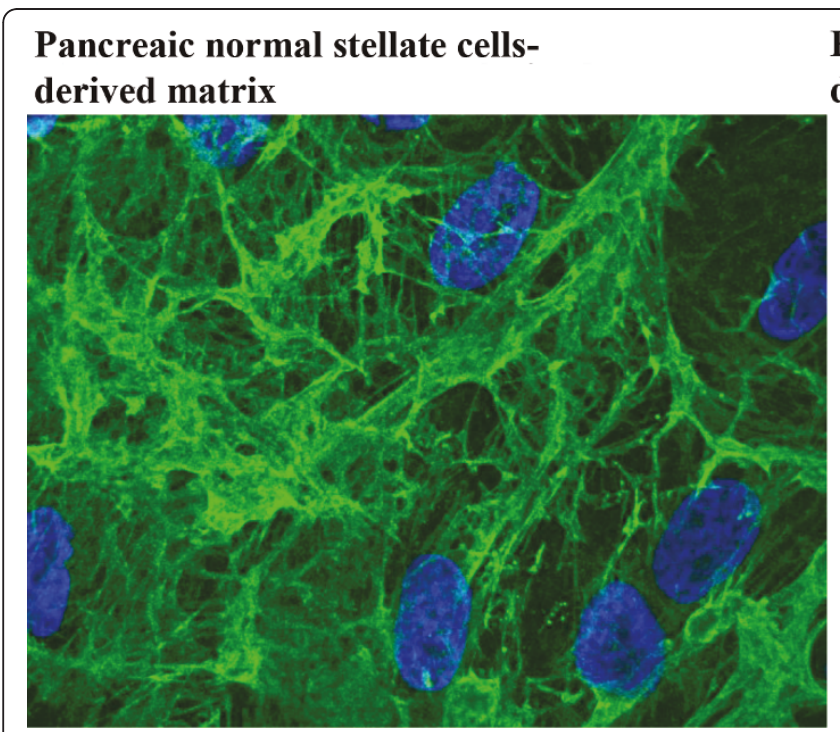

\section{Pancreatic adenocarcinoma associated fibroblasts- derived matrix}

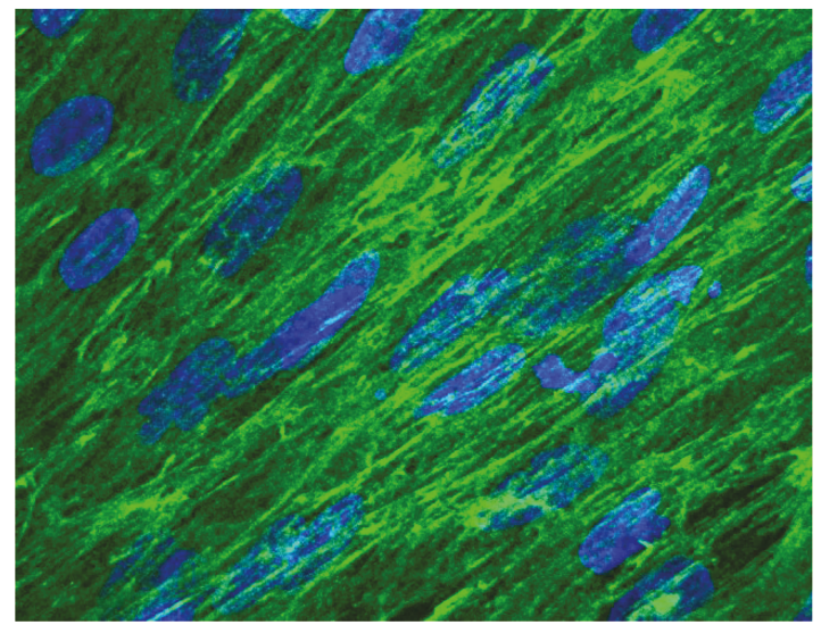

Figure 2 Human pancreatic normal stellate cells and adenocarcinoma-derived ECMs resemble FAP and FAP ${ }^{+}$ECMs, respectively. Human normal pancreatic stellate cells and pancreatic tumor-associated fibroblasts were isolated from fresh surgical tissue samples

corresponding to matched (from the same case) normal pancreas (at least $2 \mathrm{~cm}$ away from the tumor) and pancreatic adenocarcinoma. Similar to images shown in Figure 1B, un-extracted human fibroblastic pancreas matrices (anti-fibronectin in green) were subjected to indirect immunofluorescence while cells' nuclei were labeled with DAPI (blue). Note how human pancreatic adenocarcinoma-associated fibroblasts produced ECMs oriented in parallel patterns, which are similar to the patterns formed by FAP ${ }^{+}$matrices while normal pancreatic stellate cellsderived matrices resemble FAP- ECMs. 
matrices. This result supports the notion suggesting that $\mathrm{FAP}^{+}$fibroblast-derived matrices effectively recapitulate tumor stromal ECMs and that perhaps these matrices also have the capacity of producing matrices permissive/ inductive of pancreatic tumorigenesis.

\section{Stromal FAP modulates the expression levels of assorted ECM proteins}

The ECM proteins and endogenous desmoplastic proteins ( $\alpha$-SMA) have been known to be up-regulated in pancreatic stromal reactions (desmoplasia) and play an active role in tumorigenesis [40]. The levels of ECM proteins (tenascin $C$, collagen I and fibronectin) and cellular $\alpha$-SMA potentially underlying the matrix differences mediated by FAP were measured on the assorted un-extracted matrices (Figure 3). The expressions of $\alpha$-SMA, fibronectin, and collagen I were significantly up-regulated in $\mathrm{FAP}^{+}$matrix compared to FAP $^{-}$matrix $(\mathrm{p}=0.009, \mathrm{p}=0.002, \mathrm{p}=0.001$, respectively), while tenascin $\mathrm{C}$ was significantly down-regulated in $\mathrm{FAP}^{+}$matrix $(\mathrm{p}=0.001)$. Thus FAP expression in fibroblasts during matrix production alters ECMs composition, as well as its topography (e.g., fibronectin-fiber orientation). Interestingly, compared with FAP $^{-}$, inhibition of FAP enzymatic activity during FAP + matrix production enhanced fibronectin and $\alpha$-SMA expression ( $\mathrm{p}=0.04$ and $\mathrm{p}=0.04$, respectively) to

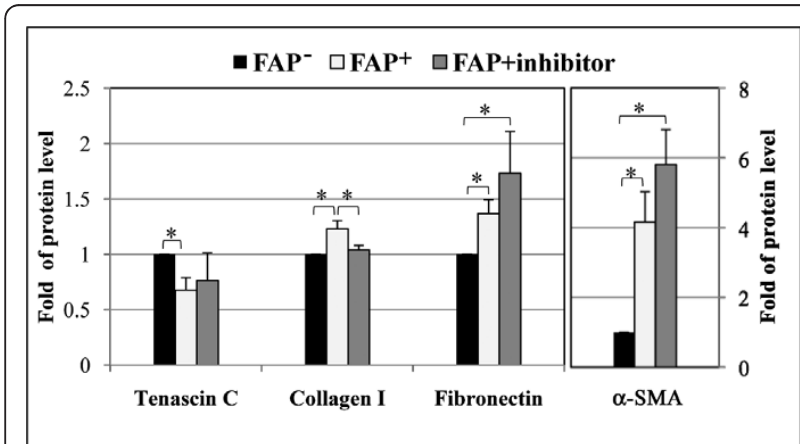

Figure 3 FAP modulates the expression levels of stromal $\alpha$ SMA and assorted ECM molecules. Western analyses were used to determine the levels of desmoplastic marker $\alpha$-SMA and assorted ECM proteins underlying the matrix differences mediated by FAP expression. The normalized fold ratios of the selected proteins by loading controls ( $\beta$-actin or GAPDH) were assigned as one arbitrary unit. Compared to FAP- matrix proteins, $\alpha$-SMA, fibronectin, and collagen I were significantly up-regulated in $\mathrm{FAP}^{+} 3 \mathrm{D}$ matrices $(\mathrm{p}=$ $0.009, p=0.002, p=0.001$, respectively), while tenascin $C$ was significantly down-regulated $(p=0.001)$. Note that although collagen I levels were rescued $(p=0.007$ ) by inhibition of FAP activity during matrix production (FAP+inhibitor), levels of expression of fibronectin and $\alpha$-SMA were only significantly increased when compared to FAP' ( $p=0.04$ in both cases) but not to $\operatorname{FAP}^{+}\left(p=0.32\right.$ and $p=0.61$, respectively). ${ }^{*}$ denotes statistical significance. levels comparable to the ones observed in $\mathrm{FAP}^{+}$cultures in the absence of the inhibitor. In fact, the $\mathrm{P}$ values for $\mathrm{FAP}^{+}$vs. $\mathrm{FAP}^{+}$inhibitor were 0.32 and 0.61 for fibronectin and $\alpha$-SMA, respectively. On the other hand, blocking FAP activity during $\mathrm{FAP}^{+}$matrix production significantly down-regulated collagen I ( $\mathrm{p}=$ 0.007), bringing the levels of this ECM protein back to levels similar to the ones observed in $\mathrm{FAP}^{-}$matrix. These results suggest that collagen I production may be FAP activity dependent (Figure 3 ).

\section{$\mathrm{FAP}^{+}$3D matrices promote the invasiveness of pancreatic} cancer cells

To determine the effects of the ECM on the invasive behavior of cancer cells, time-lapse acquisition assays were performed using pancreatic cancer cell lines that are known for their distinct invasive and metastatic potentials in vivo [41]. The more metastatic cell lines (Capan-1, Panc-1) and the less aggressive cells (AsPC-1, HPAF-II) were plated onto matrices, and their behaviors were measured for average velocity (AV), net path distance (D), path trajectory $(\mathrm{T})$, and directionality (D/T ratio) (Figure 4). The invasive behaviors of AsPC-1 (AV $=5.1 \pm 0.7, \mathrm{D}=9.5 \pm 2.9, \mathrm{~T}=54.8 \pm 5.0)$ and HPAF-II cells $(\mathrm{AV}=5.5 \pm 1.7, \mathrm{D}=16.6 \pm 4.8, \mathrm{~T}=58.1 \pm 18.1)$ were found to be less effective than the behaviors of Capan-1 (AV = $11.3 \pm 0.7, \mathrm{D}=32.2 \pm 0.7, \mathrm{~T}=120.8 \pm$ 7.9) and Panc- 1 cells $(\mathrm{AV}=12.0 \pm 1.4, \mathrm{D}=94.1 \pm 13.1$, $\mathrm{T}=128.2 \pm 15.0$ ) within the $\mathrm{FAP}^{+}$matrix. The greater average velocity of Capan-1 and Panc-1 correlated with their known enhanced ability to metastasize in vivo [41]. Although Capan-1 and Panc-1 cells presented similar velocities, they showed significant differences in their movement patterns as Panc-1 cells invaded using greater directional motilities $(\mathrm{D} / \mathrm{T}=0.72 \pm 0.05)$ compared to the more random paths taken by the Capan- 1 cells $(\mathrm{D} / \mathrm{T}$ $=0.28 \pm 0.02, \mathrm{p}<0.001)$. However, no significant differences in velocity or directionality were observed using these cells cultured within the $\mathrm{FAP}^{-}$matrices (not shown).

In order to question whether $\mathrm{FAP}^{+}$matrix effects promoting cell motility of invasive pancreatic cancer cells (i.e., Panc-1) are specific for pancreatic cancers, we repeated this series of experiments using three well characterized breast cell lines. Additional file 3, Fig. S3 shows that compared to immortalized normal MCF-10A $(\mathrm{AV}=7.59 \pm 1.3, \mathrm{D} / \mathrm{T}=0.348 \pm 0.09)$ and tumorigenic MCF-7 (AV $=4.88 \pm 0.65, \mathrm{D} / \mathrm{T}=0.17 \pm 0.042)$, highly invasive MDA-MB-231 cells moved faster $(\mathrm{AV}=12.0$ $\pm 1.0, \mathrm{p}=0.04, \mathrm{p}<0.001$, respectively) and more direct $(\mathrm{D} / \mathrm{T}=0.68 \pm 0.04, \mathrm{p}=0.001, \mathrm{p}<0.001$, respectively) on $\mathrm{FAP}^{+}$matrix. The results demonstrate that $\mathrm{FAP}^{+}$matrix effects may be important in neoplasias other than just pancreatic cancers. 


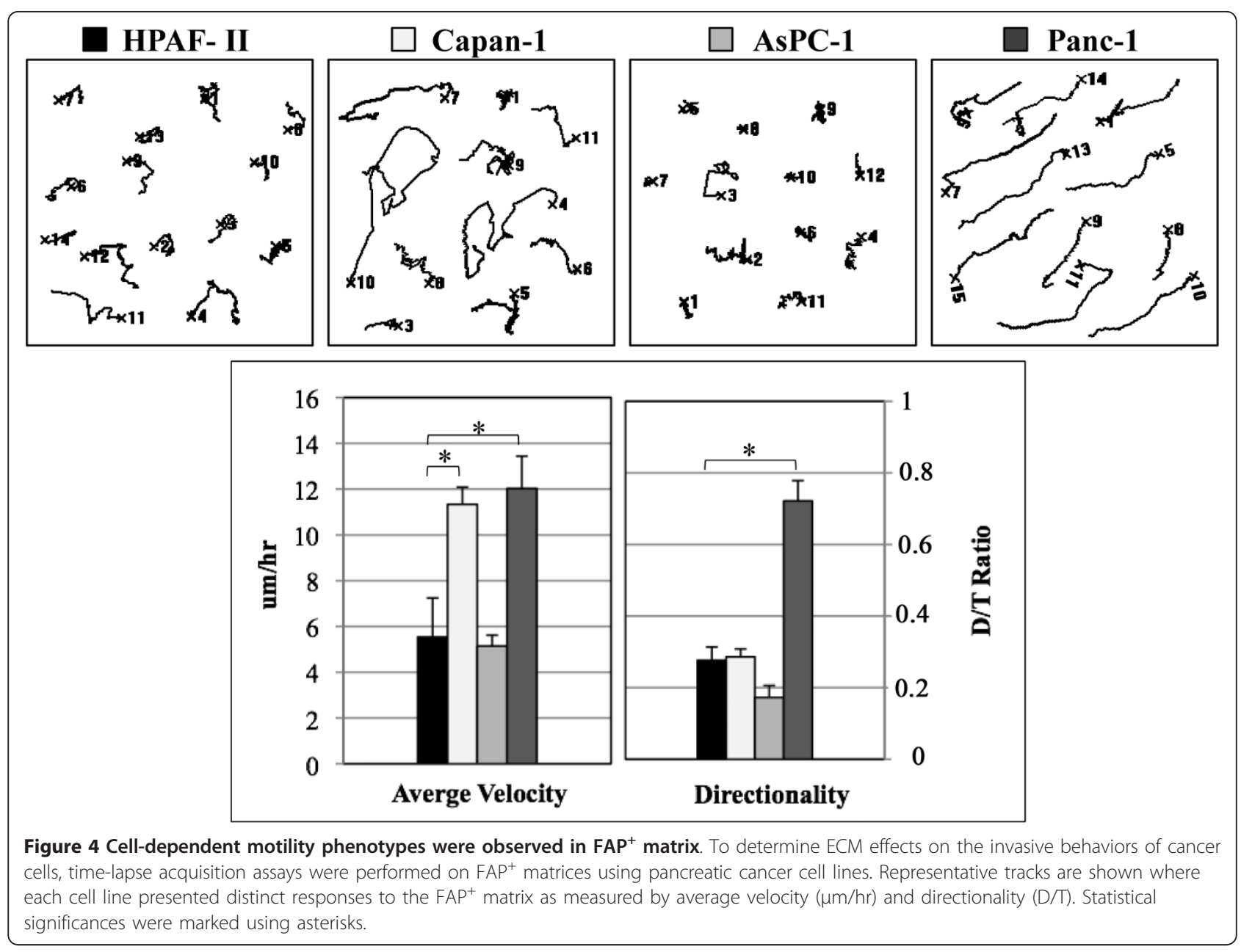

In summary, $\mathrm{FAP}^{+} 3 \mathrm{D}$ matrices represent a permissive environment for pancreatic (and breast cancer) invasion, and perhaps these matrices play an equally important role along with the epithelial cell component. Given their matrix-induced velocity and persistent directionality, Panc-1 (and in some instances MDA-MB-231) cells were selected for the further studies.

\section{$\mathrm{FAP}^{+}$3D matrices induce enhanced invasion behaviors} upon Panc-1

To test the contribution of FAP in the matrix-induced permissive tumor behavior, Panc-1 cells were seeded onto the three distinct matrices produced from the $\mathrm{FAP}^{-}, \mathrm{FAP}^{+}$, or FAP+inhibitor fibroblasts (Figure 5). Compared to cells in $\mathrm{FAP}^{-}$matrix $(\mathrm{AV}=7.8 \pm 0.8, \mathrm{D} / \mathrm{T}$ $=0.36 \pm 0.04)$, Panc -1 cells presented greater velocity and directional motility within $\mathrm{FAP}^{+}$matrix $(\mathrm{AV}=12.0$ \pm 1.4 and $\mathrm{D} / \mathrm{T}=0.72 \pm 0.06)(\mathrm{p}=0.05$ and $\mathrm{p}<0.001$, respectively). In addition, directionality was significantly attenuated on FAP+inhibitor matrix $(\mathrm{D} / \mathrm{T}=0.52 \pm 0.06$, $\mathrm{p}=0.01$ ), with a minor inhibition in the velocity $(\mathrm{AV}=$
$9.1 \pm 1.6, \mathrm{p}=0.19)$. These results demonstrate that velocity and directionality of cells depend on the type of ECM, which can differ if the matrix-producing fibroblasts express FAP or not. In addition, these results suggest that while velocity is FAP dependent regardless of its activity, directionality is strictly dependent on FAP enzymatic activity.

\section{Matrix-mediated invasive phenotypes are regulated by $\beta 1$-integrins}

Integrins are the major receptors that link the ECM tumor microenvironment with the migrating cancer cell. Given the enhanced expression of ECM proteins and rearranged fibronectin fiber orientation in $\mathrm{FAP}^{+}$matrix, the contribution of integrins responsible for the invasiveness of Panc-1 on matrix was investigated by time-lapse acquisition assays performed in the presence of functional blocking agents, including the $\beta_{1}$-integrin antibody mAb13 and the $\alpha_{5} \beta_{1}$ integrin blocking peptide ATN-161 (Figure 6). Compared to the control experiment using rabbit serum (AV $=13.55$ $\pm 2.25, \mathrm{D} / \mathrm{T}=0.64 \pm 0.07$ ), inhibition of $\beta_{1}$-integrins 


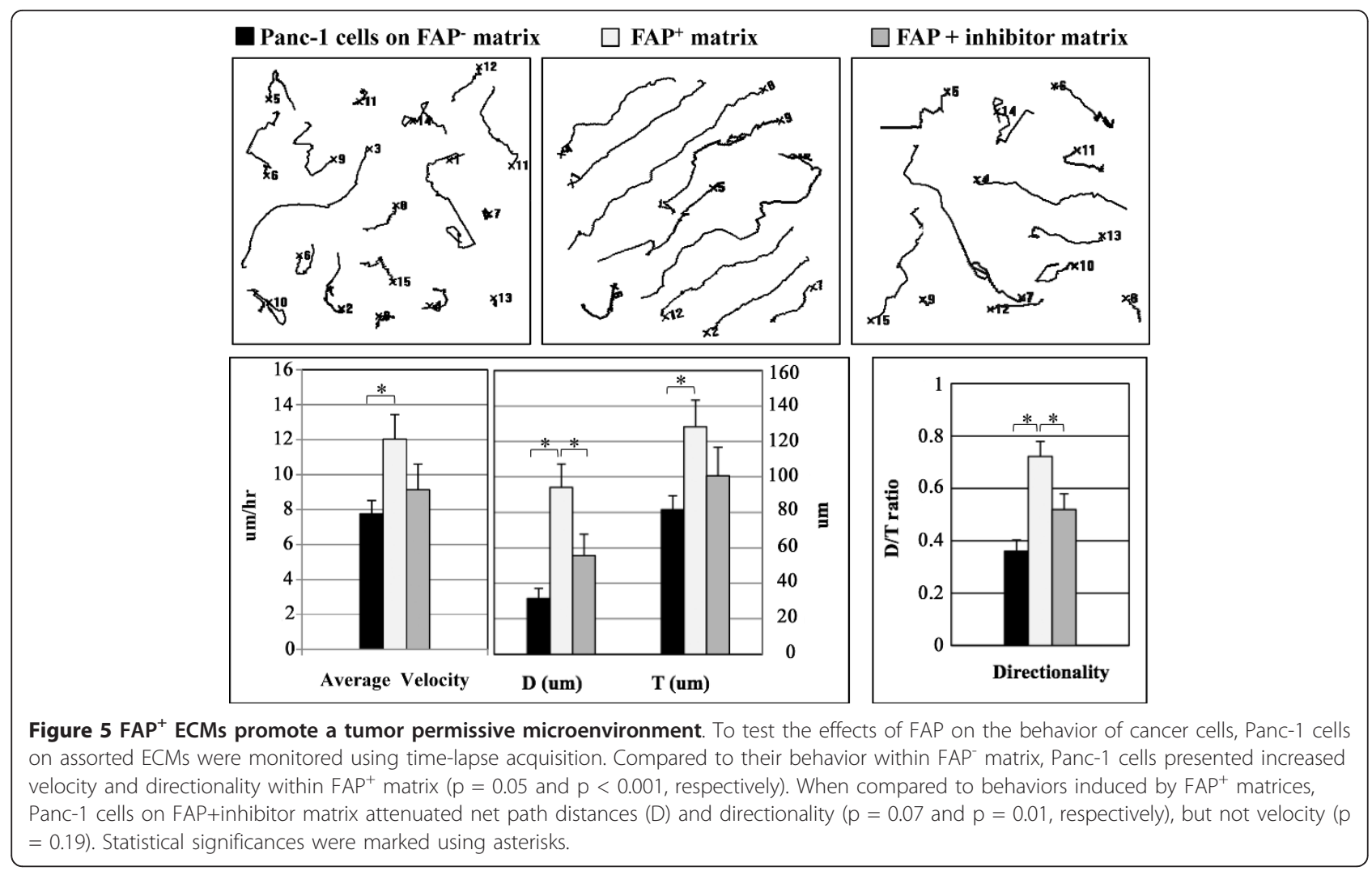
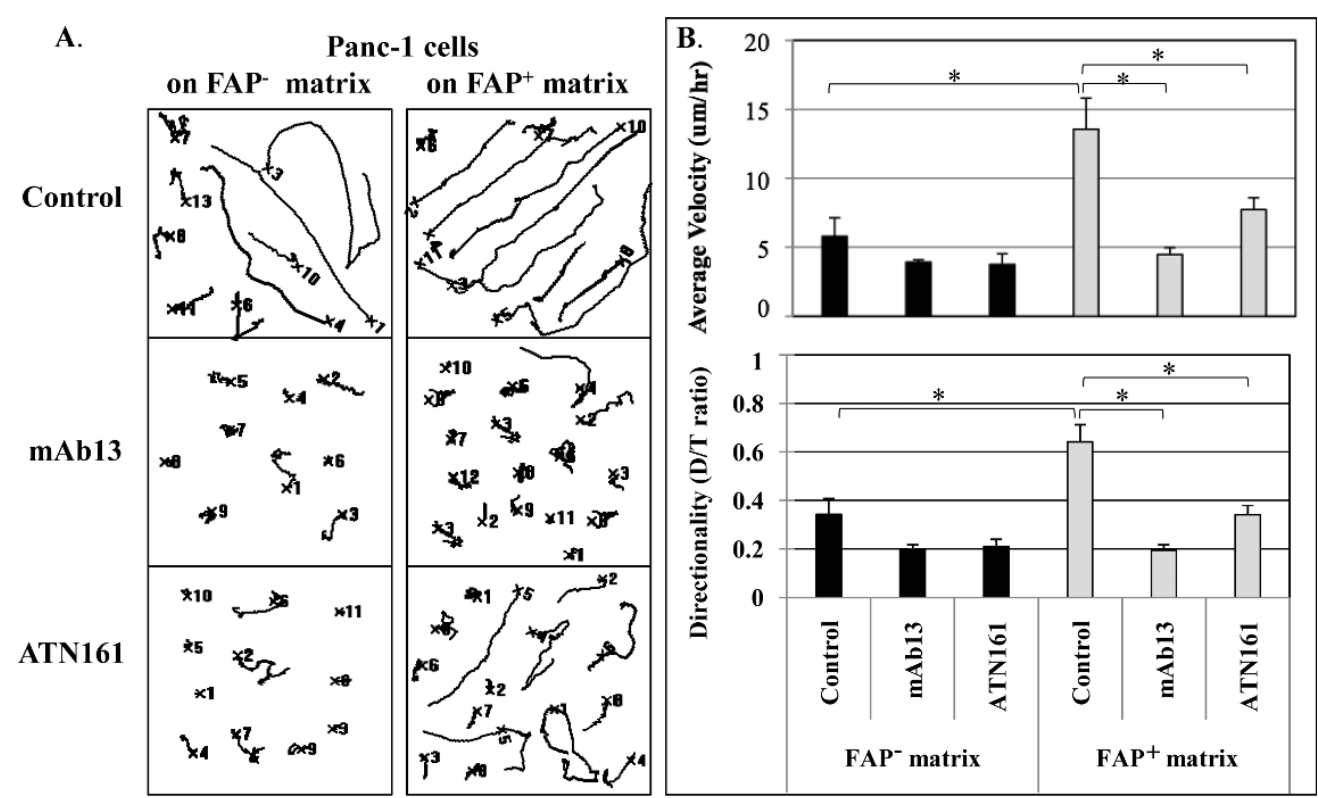

Figure 6 Matrix-mediated Panc- 1 invasive phenotypes are regulated by $\boldsymbol{\beta}_{1}$-integrin. To determine the engagement of integrins for the invasiveness of Panc- 1 in $\mathrm{FAP}^{+}$matrix, time-lapse acquisition assays were performed in the presence of functional blocking $\beta_{1}$-integrin antibody mAb13 and blocking peptide ATN-161. (A) Panels are shown representative examples of migration tracks of individual cells invading through assorted matrices. (B) Distinct responses of Panc-1 cells to the integrin inhibition were measured by average velocity and directionality. Compared to the control experiment using rabbit serum, inhibition of $\beta_{1}$-integrins significantly attenuated both velocity $(67 \%$ inhibition, $p<$ $0.001)$ and directionality (70\% inhibition, $p<0.001$ ) of Panc-1 cells in $\mathrm{FAP}^{+}$but not in FAP'matrix $(p=0.07$ and $p=0.06$, respectively). In addition, specific inhibition of $\alpha_{5} \beta_{1}$-integrin decreased both velocity (43\% inhibition, $\left.p=0.002\right)$ and directionality $(53 \%$ inhibition, $p<0.001)$ of Panc- 1 cells on $\mathrm{FAP}^{+}$matrix. Statistical significances were marked using asterisks. 
significantly attenuated both velocity $(\mathrm{AV}=4.46 \pm 0.49$, $67 \%$ inhibition, $\mathrm{p}<0.001)$ and directionality $(\mathrm{D}=0.19 \pm$ $0.03,70 \%$ inhibition, $\mathrm{p}<0.001$ ) of Panc- 1 cells on $\mathrm{FAP}^{+}$ matrix. However, these significant inhibitions were not observed on cells using FAP ${ }^{-}$matrix $(\mathrm{p}=0.07$ and $\mathrm{p}=$ 0.06 , respectively). This result suggests that $\beta_{1}$-integrin is an important regulator of tumor cell motility in $\mathrm{FAP}^{+}$but not $\mathrm{FAP}^{-}$matrices. Similar to results above, questioning the matrix specific effect on only pancreas tumorigenesis, here we decided to test $\mathrm{FAP}^{+}$matrix motility effects imparted upon MDA-MB-231 cells in the presence or absence of mAb-13. Results suggest that the observed FAP ${ }^{+}$matrix induced increase in MDA-MB-231 motility is also dependent on $\beta_{1}$-integrin activity (Additional file 4, Fig. S4).

Given the enhanced expression and spatial orientation of fibronectin in $\mathrm{FAP}^{+}$matrix, the importance of the fibronectin receptor $\alpha_{5} \beta_{1}$-integrin was also tested. Inhibition of $\alpha_{5} \beta_{1}$-integrin using ATN-161 showed significant decrease in the $\mathrm{FAP}^{+}$matrix-induced invasive behavior of Panc-1 cells (Figure 6). Compared with controls, inhibition of $\alpha_{5} \beta_{1}$-integrin decreased both velocity (AV $=7.73 \pm 0.84$, $43 \%$ inhibition, $\mathrm{p}=0.002)$ and directionality $(\mathrm{D}=0.34 \pm$ $0.03,53 \%$ inhibition, $\mathrm{p}<0.001$ ) of cells on $\mathrm{FAP}^{+}$matrix, although not to the same extent as that of more general integrin inhibitors. Given the incomplete abrogation of invasive behavior of Panc-1 cells in the presence of ATN161 , it is possible that additional $\beta_{1}$-integrins could also contribute to pancreatic cancer invasion facilitated by the $\mathrm{FAP}^{+} 3 \mathrm{D}$ matrices. In summary we concluded that, since the enhanced motility of Panc- 1 cells on $\mathrm{FAP}^{+} 3 \mathrm{D}$ matrices can be significantly reversed by blocking the function of $\beta_{1}$-integrins, a potential mechanism of matrix mediated tumor invasion is an attractive possibility.

\section{$\mathrm{FAP}^{+}$-dependent enhanced invasion behavior of Panc- 1 is} regulated by the $\beta_{1}$-integrin/FAK signaling pathway

Integrin-mediated signaling pathways are often associated with AKT and/or FAK effectors, resulting in proliferation, survival, and invasion of tumor cells [42]. To determine the downstream components of $\beta_{1}$-integrins, Panc- 1 cells were cultured within assorted $3 \mathrm{D}$ matrices and the constitutive activity levels of both AKT and FAK were analyzed by the ratios of $\mathrm{pS}^{473}-\mathrm{AKT} /$ total $\mathrm{AKT}$ and $\mathrm{pY}^{397}$-FAK/ total FAK, respectively (Figure 7). As shown in Figure 7A, constitutive FAK activity levels of Panc- 1 cells cultured within both $\mathrm{FAP}^{+}$and FAP+inhibitor matrices were significantly up-regulated $\sim 1.5$ fold compared to its activity in FAP $^{-}$matrix ( $\mathrm{p}=0.007$ and $\mathrm{p}=0.03$, respectively). When activity levels were compared for Panc-1 cells cultured within the assorted matrices in the presence or absence of mAb13, a significant down-regulation of constitutive FAK activity levels under $\beta_{1}$-integrins inhibition was observed in all three matrices $\left(\mathrm{p}=0.02, \mathrm{p}=0.002, \mathrm{p}=0.02\right.$ for $\mathrm{FAP}^{-}$

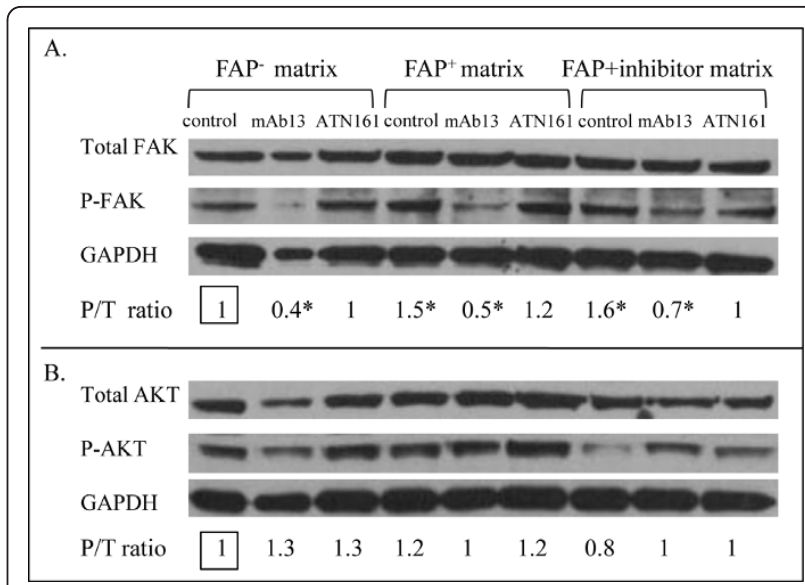

Figure $7 \mathrm{FAP}^{+}$matrix-induced Panc-1 invasion is dependent of FAK. Panc-1 cells were cultured within the assorted matrices for 2 days in the presence of mAb13, ATN-161, or rabbit sera. The specific activity of the kinases was calculated as the ratio of the scanned optical densities of the phosphorylated forms divided by total expression levels $(P / T)$. The fold of $P / T$ ratios being assessed obtained from FAP ${ }^{-}$matrices (square box) was assigned as one arbitrary unit. (A) Constitutive FAK activity levels of Panc-1 cells induced by $\mathrm{FAP}^{+}$matrix were up-regulated by $\sim 1.5$ fold ( $p=0.007$ ). Inhibition of $\beta 1$-integrin activity significantly blocked the FAK activity levels of Panc- 1 cells cultured within both FAP' and FAP matrices ( $p=0.02$ and $p=0.002$, respectively). However, inhibition of $\alpha_{5} \beta_{1}$-integrin showed no significant changes in FAK activity levels (all $p>0.3$ ). (B) AKT activity in Panc-1 cells on matrices remained unchanged in the presence or absence of inhibitory agents. Statistical significances were marked using asterisks.

, $\mathrm{FAP}^{+}, \mathrm{FAP}+$ inhibitor matrices, respectively). However, constitutive levels of AKT activity in Panc-1 cells cultured within the various matrices remained unchanged (all $\mathrm{p}>$ 0.18 , Figure $7 B$ ). In addition, inhibition of $\alpha_{5} \beta_{1}$-integrin with ATN-161 did not show any changes in the activities of FAK or AKT (all p > 0.2), suggesting that the specific integrin contributions to the total AKT and FAK activity levels are undetectable by this method, nevertheless, ATN-161 effects were shown in the motility assay (Figure 6). In summary, up-regulation of FAK activity in Panc-1 cells on $\mathrm{FAP}^{+}$matrix and down-regulation of its activity by function blocking $\beta_{1}$-integrin suggest that the FAP ${ }^{+}$-dependent enhanced invasion behavior of Panc- 1 is regulated by the $\beta_{1}$-integrin/FAK signaling pathway, and although $\alpha_{5} \beta_{1}$-integrin seems to play a role, additional $\beta_{1}$ integrins may also participate in this regulatory process.

\section{Discussion}

In this work, we provide evidence that FAP is important for remodeling a permissive stromal ECM that supports pancreatic (and perhaps also breast) cancer invasion in vitro. The experimental approach used to study the role of FAP in tumor invasion utilized an in vivo-like 3D matrix system that has been shown to effectively 
recapitulate stromal ECMs from various murine and human tissues $[21,28,43]$. Fibroblasts-derived 3D matrix system can avoid the flat surface of a tissue culture dish which impose an artificially rigid environment onto the cell [44]. On recent studies analyzing the direct effects of tumor stromal ECMs on cancer cell behavior, we demonstrated (among other things) that different breast cancer cell lines present distinct cell motility phenotypes when cultured within tumor-associated ECMs [37]. Here we also performed assays using the same breast cancer lines on our $\mathrm{FAP}^{+}$matrices and found that $\mathrm{FAP}^{+}$ matrices effectively recapitulate many aspects of tumorassociated ECMs (data shown in supplemental material). Thus $\mathrm{FAP}^{+}$matrices were utilized as a stromal landscape to study matrix-induced pancreatic (and in some instances breast) cancer cell behaviors.

In this study, we observed that $\mathrm{FAP}^{+}$fibroblast-derived matrices presented higher organization levels of fibers when compared to $\mathrm{FAP}^{-}$matrices. Importantly, we showed that $\mathrm{FAP}^{+}$matrices contain parallel fiber organization features that are reminiscent of tumor-associated ECMs of pancreatic desmoplastic tissues associated with pancreatic adenocarcinoma looking at human normal and tumor ECMs both in vivo and in vitro. The observed enhanced directionality and velocity of cancer cells invading through $\mathrm{FAP}^{+} 3 \mathrm{D}$ matrices was effectively reversed in matrices produced from $\mathrm{FAP}^{+}$fibroblasts in the presence of FAP enzymatic inhibitor. By determining alterations in collagen at the vicinity of tumors in vivo, it has been suggested that a strong relationship exists between both collagen density and matrix architectural organization and observed increased breast tumorigenesis [22]. Likewise, tumor-associated collagen features similar to the above-mentioned were observed by depleting FAP in vivo [45]. Interestingly, our human pancreatic adenocarcinoma-associated fibroblast ECMs, as well as our $\mathrm{FAP}^{+}$3D matrices in vitro, also presented the parallel organized patterns highlighted by the two studies above. These facts reinforce the notion that our in vitro models may be regarded as being highly relevant.

Our FAP+inhibitor matrices resembled $\mathrm{FAP}^{-}$matrices with lower ECM levels of organization and supported relatively impeded tumor cell behaviors. We also report that inhibition of $\beta_{1}$-integrins abrogates the FAP ${ }^{+}$ECM facilitated invasive capabilities of pancreatic and breast tumor cells, suggesting that a cell-matrix $\beta_{1}$-integrin engagement is important for this $\mathrm{FAP}^{+}$matrix-dependent process. We elucidated a potential molecular mechanism underlying the enhanced pancreatic cancer cell motility mediated by $\mathrm{FAP}^{+}$matrix. We found that FAP remodels the extracellular matrices through alterations of ECM proteins levels, as well as through increased fibronectin fiber patterned orientation. FAP expression regulates tenascin $\mathrm{C}$, collagen $\mathrm{I}$, fibronectin and $\alpha$-SMA expressions, all known to play important roles in pancreatic tumorigenesis $[7,46]$. FAP activity seems to be important for the positive collagen I and the negative tenascin $\mathrm{C}$ regulation, yet absence of FAP activity seems to significantly block collagen I while enhancing fibronectin and $\alpha$-SMA levels of expression. Our results suggest that FAP enzymatic activity plays a role not only in regulating fiber orientation but also in regulating expression levels of collagen I. Moreover, we were able to distinguish among FAP expression and/or activity dependent functions in regulating stromal markers. When measuring the levels of collagen I expression, we observed that, while FAP activity is important to both fibronectin and collagen architectural fiber organization, this activity is mostly important for assessing collagen I as opposed to fibronectin (or $\alpha$-SMA) levels of expression. In summary, we observed that both FAP expression and/or activity dependent functions can regulate ECMs compositions.

Interestingly, we learned that the velocity of the migrating cancer cells is dependent on FAP expression regardless of its activity, whereas the latter is crucial for directionality. The observed change in architecture and the levels of components of the ECM leads to enhanced ECM permissiveness, which facilitates pancreatic cancer invasiveness via $\beta_{1}$-integrin engagement. Interestingly, our results using MDA-MB-231 cells were comparable to the ones observed with Panc-1, and thus we concluded that fibroblastic FAP-dependent matrix alterations and the importance of $\beta_{1}$-integrin in the regulation of cancer cell motility are effects that are not necessarily restricted to pancreatic cancers and that additional cancers such as breast, where stromal FAP expression levels have been shown to be increased [47], show similar behaviors. Furthermore, $\mathrm{FAP}^{+}$matrixinduced regulatory molecules in cancer cells revealed that it is associated with an increased activation of FAK that is independent of AKT activity. Because $\beta_{1}$-integrins are major receptors responsible for ECM assembly, these results suggest that FAP remodels ECM fibers to provide directional paths for pancreatic (and other cancer, i.e., breast) cells to engage $\beta_{1}$-integrin/FAK for invasion. As a response to altered signals from the tumor stroma, cancer cell behavior seems to be influenced through patterning of the underlying matrix, resulting in track-dependent cellular migration. Conversely, the inhibition of $\alpha_{5} \beta_{1}$-integrin function only partially affected $\mathrm{FAP}^{+}$matrix-induced Panc-1 invasion. This specific integrin inhibition did not significantly alter the constitutive FAK activation seen in Panc-1 cells cultured into $\mathrm{FAP}^{+}$matrices, suggesting that additional members of the $\beta_{1}$-integrin family are also responsible for the matrix-induced effects. Importantly, the changes in the ECM produced by $\mathrm{FAP}^{+}$fibroblasts effectively 
recapitulate many aspects of stromal ECMs, including increased tumorigenic behaviors [37], enhance ability to metastasize in vivo [41], promote epithelial cancer cells to move along insoluble tumor-associated ECM fibers leading them towards the intravasation sites during metastasis [48], and recapitulate pancreatic stromal characteristics, such as increased collagen I expression and up-regulation of desmoplastic marker $\alpha$-SMA [49].

\section{Conclusions}

Our data suggests that cancer cell invasiveness can be affected by alterations in the tumor microenvironment. We provide evidence that FAP is important for remodeling a permissive stromal ECM to produce directional paths for pancreatic (and breast) cells that engage $\beta_{1}$ integrin/FAK for invasion. Therefore, our observations imply that a better understanding of the changes in stromal fibroblasts and their influence on epithelial tumor cell behavior can lead to novel strategies for the prevention and treatment of cancer. The identification of fibroblastic 3D-dependent signaling pathways may be important to block the transition to a permissive microenvironment and even reverse stromal fibroblast-dependent neoplasia [44]. This study provides the pre-clinical rationale that inhibition of FAP proteolytic activity and selected $\beta_{1}$ integrin family members in combination may abrogate the invasive capabilities of pancreatic tumors by interfering with the architectural organization of tumor-associated ECMs and disrupting the tumor-stromal interactions.

\section{Additional material}

Additional file 1: Figure S1; FAP is selectively overexpressed in tumor stromal fibroblasts. (A) In human pancreatic cancer patient samples, FAP is highly expressed in stromal fibroblasts (red arrows) but not in epithelial tumor components (black arrows) [18]. A parallel patterned ECM organization $\left(^{*}\right)$ is observed within the desmoplastic stromal reaction. (B) In a xenograft mouse model, human pancreatic cancer cell lines (HPAF-II, Capan-1, AsPC-1, and Panc-1) also induced murine FAP expression in the tumor stroma but not in tumor cells. Hematoxylin (blue) was used for counterstaining.

Additional file 2: Figure S2; $\mathrm{FAP}^{+}$fibroblasts affect the architectural patterns of collagen I fiber organization. Un-extracted matrices were subjected to indirect immunofluorescence using a collagen I antibody (green) and their nuclei stained using DAPI (blue). Note FAP ${ }^{+}$fibroblasts produced ECM fibers with enhanced parallel patterns compared to both FAP $^{-}$and FAP+inhibitor matrices

Additional file 3: Figure S3; A cell type dependent motility is observed in $\mathrm{FAP}^{+}$matrices using immortalized and neoplastic breast cell lines. To test the general effect of $\mathrm{FAP}^{+}$matrices in promoting motility of invasive cancer cells, three human breast cell lines (immortalized normal MCF-10, tumorigenic MCF-7, and invasive MDAMB-23) were assessed. Note that compared to MCF-10A and MCF-7, invasive MDA-MB-231 cells presented a faster $(p=0.04, p<0.001$, respectively) and more direct ( $p=0.001, p<0.001$, respectively) motility within these permissive 3D matrices. Statistical significances were marked using asterisks.

Additional file 4: Figure S4; Matrix-mediated MDA-MB-231 invasive phenotypes are regulated by $\boldsymbol{\beta}_{1}$-integrin. To confirm the engagement of integrins for the invasive characteristics of MDA-MB-231 on $\mathrm{FAP}^{+}$ matrix, time-lapse motility assays were performed in the presence of anti-integrin $\beta_{1}$ antibody mAb13, the $\alpha \beta_{3}$ specific integrin antibody LM609, and rabbit sera as a control. (A) Panels are shown representative examples of migration tracks of individual cells invading though assorted matrices. (B) Distinct responses of MDA-MB-231 cells to the integrin inhibition were measured by average velocity and directionality. Compared to the control, inhibition of $\beta_{1}$-integrins significantly attenuated both velocity $(p<0.001)$ and directionality $(p<0.001)$ of cells in $\mathrm{FAP}^{+}$but not in FAP' matrix. In addition, specific inhibition of $\alpha \beta_{3^{-}}$ integrin decreased velocity $(p<0.001)$ but not directionality on FAP ${ }^{+}$ matrix. Statistical significances were marked using asterisks.

\section{Acknowledgements and Funding}

We thank Dr. Wen-Tien Chen, Dr. Teresa Ramirez-Montagut, Dr. William Bachovchin, and Dr. Kenneth Yamada for providing reagents. We also thank Dr. Fang Zhu for statistical analysis assistance. This work was supported by grants from the National Institutes of Health CA090468 (JDC), CA122301 (JDC), CA113451 (EC) and CA06927, by an Appropriation from the Commonwealth of Pennsylvania, as well as by Fox Chase Cancer Center's Internal Director's Fund and the Ewing Trust for Pancreatic Cancer research.

\section{Author details}

'Department of Medical Oncology, Fox Chase Cancer Center, 333 Cottman Avenue, Philadelphia, Pennsylvania 19111, USA. ${ }^{2}$ Cancer Biology Program, Fox Chase Cancer Center, 333 Cottman Avenue, Philadelphia, Pennsylvania 19111, USA.

\section{Authors' contributions}

$\mathrm{HOL}$ performed the majority of experiments and analyses and drafted the manuscript. SRM performed the analysis of matrix fiber orientation. JFB harvested the human pancreas stellate and adenocarcinoma-associated fibroblasts, produced the human in vitro matrices, and performed the characterization analyses of these 3D ECMs. MV generated the Tet-inducible fibroblasts and provided insight while revising the manuscript. EC and JDK were responsible for the study coordination, as well as the design and interpretation of results and revision of the drafted manuscript. All authors read and approved the final manuscript.

\section{Competing interests}

The authors declare that they have no competing interests.

Received: 12 November 2010 Accepted: 13 June 2011

Published: 13 June 2011

\section{References}

1. Kiaris H, Chatzistamou I, Kalofoutis C, Koutselini H, Piperi C, Kalofoutis A: Tumour-stroma interactions in carcinogenesis: basic aspects and perspectives. Mol Cell Biochem 2004, 261(1-2):117-122.

2. Nakagawa H, Liyanarachchi S, Davuluri RV, Auer H, Martin EW, de la Chapelle A, Frankel WL: Role of cancer-associated stromal fibroblasts in metastatic colon cancer to the liver and their expression profiles. Oncogene 2004, 23(44):7366-7377.

3. Ruiter D, Bogenrieder T, Elder D, Herlyn M: Melanoma-stroma interactions: structural and functional aspects. Lancet Oncol 2002, 3(1):35-43.

4. Sato N, Maehara N, Goggins M: Gene expression profiling of tumorstromal interactions between pancreatic cancer cells and stromal fibroblasts. Cancer Res 2004, 64(19):6950-6956.

5. Ostman A, Augsten M: Cancer-associated fibroblasts and tumor growthbystanders turning into key players. Curr Opin Genet Dev 2009, 19(1):67-73.

6. Li H, Fan X, Houghton J: Tumor microenvironment: the role of the tumor stroma in cancer. J Cell Biochem 2007, 101(4):805-815.

7. Mahadevan D, Von Hoff DD: Tumor-stroma interactions in pancreatic ductal adenocarcinoma. Mol Cancer Ther 2007, 6(4):1186-1197.

8. Mueller MM, Fusenig NE: Tumor-stroma interactions directing phenotype and progression of epithelial skin tumor cells. Differentiation 2002, 70(910):486-497. 
9. Edwards DR, Murphy G: Cancer. Proteases-invasion and more. Nature 1998, 394(6693):527-528.

10. Johnsen M, Lund LR, Romer J, Almholt K, Dano K: Cancer invasion and tissue remodeling: common themes in proteolytic matrix degradation. Curr Opin Cell Biol 1998, 10(5):667-671.

11. Kalluri R, Zeisberg M: Fibroblasts in cancer. Nat Rev Cancer 2006, 6(5):392-401

12. Park JE, Lenter MC, Zimmermann RN, Garin-Chesa P, Old LJ, Rettig WJ: Fibroblast activation protein, a dual specificity serine protease expressed in reactive human tumor stromal fibroblasts. J Biol Chem 1999, 274(51):36505-36512

13. Monsky WL, Lin CY, Aoyama A, Kelly T, Akiyama SK, Mueller SC, Chen WT: A potential marker protease of invasiveness, seprase, is localized on invadopodia of human malignant melanoma cells. Cancer Res 1994, 54(21):5702-5710.

14. Mueller SC, Ghersi G, Akiyama SK, Sang QX, Howard L, Pineiro-Sanchez M, Nakahara $\mathrm{H}$, Yeh Y, Chen WT: A novel protease-docking function of integrin at invadopodia. J Biol Chem 1999, 274(35):24947-24952.

15. Wang XM, Yu DM, McCaughan GW, Gorrell MD: Fibroblast activation protein increases apoptosis, cell adhesion, and migration by the LX-2 human stellate cell line. Hepatology 2005, 42(4):935-945.

16. Cheng JD, Dunbrack RL, Valianou M, Rogatko A, Alpaugh RK, Weiner LM: Promotion of tumor growth by murine fibroblast activation protein, a serine protease, in an animal model. Cancer Res 2002, 62(16):4767-4772.

17. Cheng JD, Valianou M, Canutescu AA, Jaffe EK, Lee HO, Wang H, Lai JH, Bachovchin WW, Weiner LM: Abrogation of fibroblast activation protein enzymatic activity attenuates tumor growth. Mol Cancer Ther 2005, 4(3):351-360.

18. Cohen SJ, Alpaugh RK, Palazzo I, Meropol NJ, Rogatko A, Xu Z, Hoffman JP, Weiner LM, Cheng JD: Fibroblast activation protein and its relationship to clinical outcome in pancreatic adenocarcinoma. Pancreas 2008, 37(2):154-158.

19. Bissell MJ, Rizki A, Mian IS: Tissue architecture: the ultimate regulator of breast epithelial function. Curr Opin Cell Biol 2003, 15(6):753-762

20. Grzesiak JJ, Ho JC, Moossa AR, Bouvet M: The integrin-extracellular matrix axis in pancreatic cancer. Pancreas 2007, 35(4):293-301.

21. Amatangelo MD, Bassi DE, Klein-Szanto AJ, Cukierman E: Stroma-derived three-dimensional matrices are necessary and sufficient to promote desmoplastic differentiation of normal fibroblasts. Am J Pathol 2005, 167(2):475-488.

22. Provenzano PP, Eliceiri KW, Campbell JM, Inman DR, White JG, Keely PJ: Collagen reorganization at the tumor-stromal interface facilitates local invasion. BMC Med 2006, 4(1):38

23. Levental KR, Yu H, Kass L, Lakins JN, Egeblad M, Erler JT, Fong SF, Csiszar K, Giaccia A, Weninger W, et al: Matrix crosslinking forces tumor progression by enhancing integrin signaling. Cell 2009, 139(5):891-906.

24. Miura N, Kanayama Y, Nagai W, Hasegawa T, Seko Y, Kaji T, Naganuma A: Characterization of an immortalized hepatic stellate cell line established from metallothionein-null mice. J Toxicol Sci 2006, 31(4):391-398.

25. Castello-Cros R, Cukierman E: Stromagenesis during tumorigenesis: characterization of tumor-associated fibroblasts and stroma-derived 3D matrices. Methods Mol Biol 2009, 522:275-305.

26. Cukierman E: A visual-quantitative analysis of fibroblastic stromagenesis in breast cancer progression. J Mammary Gland Biol Neoplasia 2004, 9(4):311-324

27. Cukierman E: Cell migration analyses within fibroblast-derived 3-D matrices. In Cell migration: Developmental methods and protocols. Volume 294. Edited by: Guan J. Totowa NJ: Humana Press; 2005:79-93.

28. Cukierman E, Pankov R, Stevens DR, Yamada KM: Taking cell-matrix adhesions to the third dimension. Science 2001, 294(5547):1708-1712.

29. Pankov R, Endo Y, Even-Ram S, Araki M, Clark K, Cukierman E, Matsumoto K, Yamada KM: A Rac switch regulates random versus directionally persistent cell migration. J Cell Biol 2005, 170(5):793-802.

30. Goodman JD, Rozypal TL, Kelly T: Seprase, a membrane-bound protease, alleviates the serum growth requirement of human breast cancer cells. Clin Exp Metastasis 2003, 20(5):459-470.

31. Jin X, Iwasa S, Okada K, Mitsumata M, Ooi A: Expression patterns of seprase, a membrane serine protease, in cervical carcinoma and cervical intraepithelial neoplasm. Anticancer Res 2003, 23(4):3195-3198.

32. Iwasa S, Jin X, Okada K, Mitsumata M, Ooi A: Increased expression of seprase, a membrane-type serine protease, is associated with lymph node metastasis in human colorectal cancer. Cancer Lett 2003 199(1):91-98.

33. Ariga N, Sato E, Ohuchi N, Nagura H, Ohtani H: Stromal expression of fibroblast activation protein/seprase, a cell membrane serine proteinase and gelatinase, is associated with longer survival in patients with invasive ductal carcinoma of breast. Int J Cancer 2001, 95(1):67-72.

34. Scanlan MJ, Raj BK, Calvo B, Garin-Chesa P, Sanz-Moncasi MP, Healey JH, Old LJ, Rettig WJ: Molecular cloning of fibroblast activation protein alpha, a member of the serine protease family selectively expressed in stromal fibroblasts of epithelial cancers. Proc Natl Acad Sci USA 1994, 91(12):5657-5661.

35. Henry LR, Lee HO, Lee JS, Klein-Szanto A, Watts P, Ross EA, Chen WT, Cheng JD: Clinical implications of fibroblast activation protein in patients with colon cancer. Clin Cancer Res 2007, 13(6):1736-1741.

36. Niedermeyer J, Scanlan MJ, Garin-Chesa P, Daiber C, Fiebig HH, Old LJ, Rettig WJ, Schnapp A: Mouse fibroblast activation protein: molecular cloning, alternative splicing and expression in the reactive stroma of epithelial cancers. Int I Cancer 1997, 71(3):383-389.

37. Castello-Cros R, Khan DR, Simons J, Valianou M, Cukierman E: Staged stromal extracellular 3D matrices differentially regulate breast cancer cell responses through PI3K and beta1-integrins. BMC Cancer 2009, 9:94.

38. Levy MT, McCaughan GW, Abbott CA, Park JE, Cunningham AM, Muller E, Rettig WJ, Gorrell MD: Fibroblast activation protein: a cell surface dipeptidyl peptidase and gelatinase expressed by stellate cells at the tissue remodelling interface in human cirrhosis. Hepatology 1999, 29(6):1768-1778

39. Omary MB, Lugea A, Lowe AW, Pandol SJ: The pancreatic stellate cell: a star on the rise in pancreatic diseases. J Clin Invest 2007, 117(1):50-59.

40. Armstrong T, Packham G, Murphy LB, Bateman AC, Conti JA, Fine DR, Johnson CD, Benyon RC, Iredale JP: Type I collagen promotes the malignant phenotype of pancreatic ductal adenocarcinoma. Clin Cancer Res 2004, 10(21):7427-7437.

41. Loukopoulos P, Kanetaka K, Takamura M, Shibata T, Sakamoto M, Hirohashi S: Orthotopic transplantation models of pancreatic adenocarcinoma derived from cell lines and primary tumors and displaying varying metastatic activity. Pancreas 2004, 29(3):193-203.

42. Hsia DA, Mitra SK, Hauck CR, Streblow DN, Nelson JA, llic D, Huang S, Li E, Nemerow GR, Leng J, et al: Differential regulation of cell motility and invasion by FAK. J Cell Biol 2003, 160(5):753-767.

43. Quiros RM, Valianou M, Kwon Y, Brown KM, Godwin AK, Cukierman E: Ovarian normal and tumor-associated fibroblasts retain in vivo stromal characteristics in a 3-D matrix-dependent manner. Gynecol Oncol 2008, 110(1):99-109.

44. Beacham DA, Cukierman E: Stromagenesis: the changing face of fibroblastic microenvironments during tumor progression. Semin Cancer Biol 2005, 15(5):329-341.

45. Santos AlM, Jung J, Aziz N, Kissil JL, Puré E: Targeting fibroblast activation protein inhibits tumor stromagenesis and growth in mice. The Journal of Clinical Investigation 2009, 119(12):3613-3625.

46. Farrow B, Rowley D, Dang T, Berger DH: Characterization of TumorDerived Pancreatic Stellate Cells. J Surg Res 2009, 157(1):96-102.

47. Mersmann M, Schmidt A, Rippmann JF, Wuest T, Brocks B, Rettig WJ, GarinChesa P, Pfizenmaier K, Moosmayer D: Human antibody derivatives against the fibroblast activation protein for tumor stroma targeting of carcinomas. Int I Cancer 2001, 92(2):240-248.

48. Condeelis J, Segall JE: Intravital imaging of cell movement in tumours. Nat Rev Cancer 2003, 3(12):921-930.

49. Binkley CE, Zhang L, Greenson JK, Giordano TJ, Kuick R, Misek D, Hanash S, Logsdon CD, Simeone DM: The molecular basis of pancreatic fibrosis: common stromal gene expression in chronic pancreatitis and pancreatic adenocarcinoma. Pancreas 2004, 29(4):254-263.

\section{Pre-publication history}

The pre-publication history for this paper can be accessed here: http://www.biomedcentral.com/1471-2407/11/245/prepub

\section{doi:10.1186/1471-2407-11-245}

Cite this article as: Lee et al.: FAP-overexpressing fibroblasts produce an extracellular matrix that enhances invasive velocity and directionality of pancreatic cancer cells. BMC Cancer 2011 11:245. 